\title{
3D Peraga Ilmu Urologi Berbasis Augmented Reality
}

\author{
Aisyah Luna Maydinar Sutisna, dan Nugrahadi Ramadhani \\ Departemen Desain Produk Industri, Fakultas Arsitektur Desain dan Perencanaan, \\ Institut Teknologi Sepuluh Nopember (ITS) \\ e-mail: contraomnes1620@gmail.com, sancokbrancok@gmail.com
}

\begin{abstract}
Abstrak-Pendekatan pembelajaran konvensional memiliki berbagai kelemahan dari berbagai sudut pandang, terutama dari segi interaktivitas, mekanisme, dan cenderung bersifat pasif. Sebuah pendekatan alternatif menggunakan media diusulkan dalam bentuk pendekatan berbasis visualisasi yang mampu menyampaikan konten yang sebanding dengan pendekatan konvensional serta bersifat atraktif. Penelitian ini membahas tentang bagaimana alternatif untuk menyampaikan media pembelajaran urologi dengan menggunakan pendekatan observasional sebagai metode pengumpulan proses kebutuhan pengguna di setiap pemangku kepentingan yang ada. Adapun dasar teori yang digunakan berupa studi literatur untuk mengetahui anatomi dan fisiologi dasar urologi disertai 5 penyakit populer, pendekatan realitas tetambah (Augmented Reality), dan konsep 3D modeling. Hasil rancangan dari penelitian ini berbentuk sebuah aplikasi berbasis android yang berisikan media peragaan dengan animasi 3D dan Augmented Reality yang diharapkan mampu mempermudah pengguna memahami urologi secara singkat dan komprehensif.
\end{abstract}

Kata Kunci-Augmented Reality, Aplikasi Peragaan, Urologi.

\section{PENDAHULUAN}

$\mathrm{K}^{\mathrm{H}}$ EMAJUAN di era globalisasi membuat kemajuan di tiap bidang, hal ini tidak terkecuali pada bidang kedokteran. Dalam menempuh pendidikan di bidang kedokteran, setiap mahasiswa kedokteran harus melalui tahap pendidikan dokter muda setelah menempuh sarjana pendidikan. Pada bidang stase kedokteran sendiri terhimpun dari berbagai macam cabang keilmuan terutama urologi. Urologi merupakan sebuah cabang keilmuan dari ilmu kedokteran yang mencakup anatomi, fisiologi, biokimia, hingga patologi dari ginjal hingga uretra serta organ genital pria.

Hampir semua pembelajaran urologi dirangkum dalam bentuk buku besar. Pada bidang pendidikan kedokteran sendiri, pembelajaran tidak hanya dari buku saja, tetapi juga bisa didapatkan dari praktikum. Para mahasiswa sendiri membutuhkan biaya yang sangat besar untuk mendapatkan buku maupun melakukan praktikum dengan cadaver (mayat utuh). Selain itu, proses praktikum pada kadaver sendiri hanya bisa dilakukan di lab dan tidak bisa dibawa keluar dari lapangan lab. Menurut wawancara dari seorang dokter umum, cabang keilmuan urologi ini kurang populer karena media yang digunakan untuk pembelajaran kurang menarik sehingga membuat mahasiswa tidak tertarik mempelajari. Hal ini dapat dibuktikan bahwa konten berupa buku terlalu besar.

Konten media pembelajaran menggunakan buku merupakan cara yang kurang konvensional. Konten pada media buku terdapat buku fisik dan buku yang berbasis e-learning atau ebook. Namun banyak kekurangan tampak pada pengunaan media pembelajaraan ini ditemukan yaitu buku fisik sangat tidak praktis dan bergantung pada ukuran dari buku tersebut. Semakin banyak kontennya, semakin berat buku fisik tersebut dan sebaliknya. Lalu pada e-book ditemukan bahwa kontennya terlalu banyak dan semua konten yang ditampilkan juga bergantung pada mata sang pengguna gadget dan ukurannya karena dapat memicu kelelahan.

Bedasarkan penelitian Tech in Asia,[1] pengguna smartphone semakin meningkat pesat di setiap tahunnya. Hal ini menjadikan pemilihan media melalui aplikasi pada smartphone sangat efektif dan dapat menjangkau masyarakat luas.

Dibutuhkan banyak visualisasi menarik untuk memadukan sebuah media pembelajaran menjadi lebih menarik. Salah satunya paduan aplikasi android berbasis 3D (Tiga-dimensi). Aplikasi 3D berbasis android ini merupakan teknologi yang sedang menjadi trend yang dipadukan dengan konten pembelajaran. Biasanya, konten yang ada pada teknologi ini yaitu konten visual interaktif maupun konten teknologi pada kalangan masyarakat umum. Sebagian besar yaitu membuat game dan video. Visualisasi yang terdapat pada aplikasi 3D ini dapat memberikan detail konten yang detil. Salah satu contohnya yaitu menggunakan augmented reality (AR) sebagai media pergaan.

Augmented reality merupakan teknologi yang menggabungkan benda - benda maya yang berwujud dua dimensi ataupun tiga dimensi ke dalam sebuah lingkungan nyata tiga dimensi, lalu memproyeksikan benda - benda maya tersebut ke dalam waktu nyata (real time)[2].

Umumnya AR lebih sering dijumpai sebagai alat alternatif edukasi berupa peraga sebuah konten pembelajaran tertentu, misalnya memperagakan contoh objek yang berbentuk spatial atau berdimensi seperti gedung, makanan, planet, dan benda berdimensi lainnya.

\section{A. Identifikasi Masalah}

1. Banyak media pembelajaran buku yang ditemukan kurang komprehensif untuk dipahami para dokter muda 
2. Praktik kadaver tidak bisa dilakukan diluar lapangan operasi

3. Buku fisik sangat tidak praktis dan bergantung pada volume dari buku itu sendiri. Sedangkan buku digital bergantung pada mata penggunanya karena melelahkan.

\section{B. Rumusan Masalah}

"Bagaimana merancang sebuah panduan digital yang diterapkan dengan teknologi 3D dan AR ke media smartphone agar mempermudah para dokter muda untuk mempelajari penyakit populer urologi dengan praktis?"

\section{Batasan Masalah}

1. Ditujukan untuk dokter muda yang mengikuti sub stase urologi, mahasiswa kedokteran dan dokter umum

2. Konten yang diambil untuk peragaan $3 \mathrm{D}$ yaitu tentang 5 penyakit populer

3. Urogenital yang diambil untuk konten AR terbatas 9 organ yang disingkat menjadi 5 konten yaitu ginjal dan ureter, bladder, prostat, urethra dan penis, testis beserta vas deferens, dan epididymis.

\section{Tujuan}

Hasil perancangan ini merupakan sebuah aplikasi berbasis android dengan teknologi 3D sebagai pembantu peragaan dan teknologi Augmented Reality agar mempermudah pembelajaran Urologi secara singkat dan komprehensif. Dengan adanya teknologi tersebut, diharapkan app ini dapat membantu dokter muda mempelajari anatomi dan penyakit populer dengan baik.

\section{URAIAN PENELITIAN}

\section{A. Landasan Teori}

\section{1) Urologi}

Urologi merupakan sebuah cabang keilmuan dan ruang lingkup dari ilmu kedokteran yang mencakup anatomi, fisiologi, biokimia, hingga patologi dari ginjal hingga uretra serta organ genital pria.

Untuk perancangan ini, penulis memilih organ urogenitalia mulai dari ginjal, ureter, kantung kemih, uretra, kelenjar adrenal, serta sistem reproduksi pria meliputi testis, epididimis, prostat, penis, vas deferens, dan vesika seminalis. [3] sebagai konten augmented reality.

Sedangkan untuk konten peragaan 3D, penulis menggunakan sesuai dari informan yaitu 5 penyakit populer seperti batu saluran kencing, kanker prostat, vesicoureteral reflux (VUR), kanker kandung kencing, dan inkontinesia urin.

2) Modeling $3 D$

Modeling 3D merupakan proses pengembangan dari perhitungan matematika berupa kedalaman, ketinggian, dan kesan timbul sehingga output yang diwujudkan seperti nyata. Hasil output tersebut dinamakan model 3D. Aspek penilaian dari output model 3D yaitu level of details / LOD. [4] Level of details merupakan sebuah penilaian untuk mengetahui apakah permukaan dari sebuah model dapat terlihat jelas ketika dirender. Hal ini sangat penting karena untuk model yang merepresentasikan sebuah peragaan dan animasi, pasif maupun aktif tetap menggunakan model yang kualitas rendernya tinggi agar detil permodel dapat terlihat secara jelas. Jika model tersebut digunakan untuk thumbnail, maka model tersebut harus dirender.

\section{3) Augmented Reality}

Augmented reality memiliki arti dalam bahasa Indonesia, yaitu realitas tetambah, merupakan teknologi yang menggabungkan benda - benda maya yang berwujud dua dimensi ataupun tiga dimensi ke dalam sebuah lingkungan nyata tiga dimensi, lalu memproyeksikan benda - benda maya tersebut ke dalam waktu nyata (real time)

Umumnya teknologi augmented reality membutuhkan smartphone atau kamera sebagai pemindai, sebuah objek yang sebagai image target, lalu app yang berbasis augmented reality, dan output berupa 2D atau 3D yang akan ditampilkan melalui smartphone app. Langkah awalnya, smartphone memindai image target melalui app yang tersedia. Selanjutnya sebuah data berupa 2D atau 3D muncul pada layar smartphone.

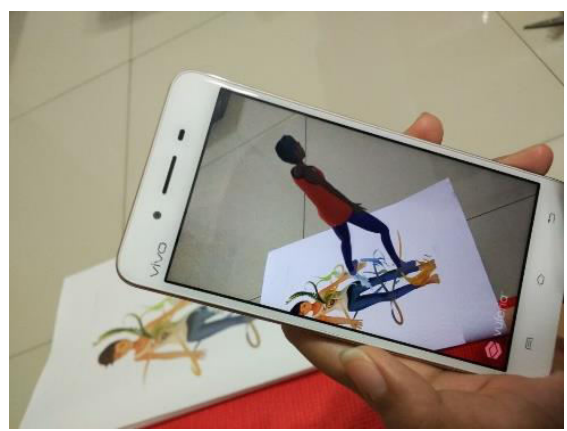

Gambar 1. Contoh penggunaan Augmented Reality menggunakan Smartphone.

Oliver Bimber dan Ramesh Raskar (2005) mendefinisikan bahwa sebuah perlakuan untuk mengintegerasikan jaringan berupa objek sintetik, dalam bentuk virtual kedalam dunia nyata. Jaringan ini memiliki hubungan spasial antara augmentasi (objek ataupun data) dengan lingkungan nyata. Augmentasi yang didapat pada dunia nyata memiliki korelasi kuat karena terdapat informasi yang akan ditampilkan layaknya holographic.

Metode yang dikembangkan pada augmented reality saat ini terbagi menjadi dua metode, yaitu marker based tracking dan markless augmented reality.

\section{4) Graphic User Interface (GUI)}

GUI (Graphic User Interface) merupakan antarmuka pada system operasi computer yang menggunakan menu grafis.dan melibatkan pengguna (user) ketika menggunakan aplikasi dengan antarmuka yang telah diterapkan seperti UI/UX.

5) $U I$

User Interface (antarmuka pengguna, atau UI) merupakam bentuk tampilan grafis yang berhubungan langsung dengan pengguna perangkat (user). Tampilan layout / tata letak UI ini dapat berbentuk fisik (nyata) yang tertera di perangkat keras atau secara virtual (digital) dan ditampilkan lewat monitor. UI sendiri merupakan fundamental dasar untuk membuat perancangan ini dikarenakan semakin mudah sebuah tampilan grafis tersebut, semakin mudah pula digunakan dengan pengguna. 


\section{6) $U X$}

User experience memiliki ranah yang lebih luas dari UI, karena ranah UX ini dimulai dengan penelitian pasar maupun pengguna yang kemudian diimplementasi kedalam sebuah interface. UI adalah bagian dari UX dimana UI merupakan produk akhir dari UX. Maka, hal ini mengartikan bahwa UX merupakan sebuah perasaan pengguna dari antarmuka dan bagaimana mereka meresponnya.

7) Studi Eksisting

\section{a. Humanoid $4 D+$}

Mengkaji pada konten augmented reality dengan sumber konten anatomi dan fisiologi dasar dalam bentuk ringkas dengan animasi 3D interaktif.

b. Anatomy Learning

Terdapat sub organ anatomi dan fisiologi berupa keterangan interaktif. Setiap keterangan terdapat tombol untuk setiap gestur berupa tapping / dragging.

\section{c. Urology-Animated Dictionarry}

Konten yang dikaji spesifik seperti kamus dalam bentuk digital disertai animasi 3D

\section{METODOLOGI PERANCANGAN}

\section{A. Wawancara Mendalam}

Wawancara dilakukan untuk mengetahui sistem pembelajaran mahasiswa kedokteran dan konten maupun insights yang diambil dalam augmented reality.

1) Dengan dosen Urologi

Lokasi : Melalui surel

Narasumber : Dr. Ishaq Hardiansyah

Perihal : Pengalaman belajar mengajar

2) Dengan stakeholder

Lokasi : Melalui platform media sosial 'Hangouts'

Narasumber : Ahmad Reza Rizkiyuda

Perihal : Indonesia dan $A R$

\section{B. Focus Group Discussion - FGD}

Focus Group Discussion diadakan untuk mengetahui sistematis pembelajaran serta pengalaman mahasiswa kedokteran terhadap stase urologi.

1.) Lokasi : SMF Urologi Fakultas Kedokteran Universitas Airlangga

Peserta : Dokter muda Fakultas Kedokteran Universitas Airlangga

Perihal : Pengalaman belajar mengajar

2.) Lokasi : Melalui platform media sosial 'Hangouts'

Peserta : Dokter muda (umum)

Perihal : Pengalaman belajar mengajar

\section{Observasi dengan metode 'Shadowing'}

Observasi bertujuan untuk mengetahui sistematik pembelajaran mahasiswa kedokteran lebih dalam serta megetahui pertimbangan media yang digunakan

Lokasi : SMF Urologi Fakultas Kedokteran Universitas Airlangga

Perihal : Kegiatan belajar mengajar

\section{Survey grafis}

Survey grafis dilakukan untuk mengetahui kejeasan dan kesesuaian ikon untuk perancangan.

Media : Google Forms

Peserta: Dokter muda dan mahasiswa kedokteran

Perihal : Kesesuaian ikon terhadap calon pengguna

\section{E. User Testing}

User testing diadakan sebagai acuan dan kelayakan perancangan ini.

Lokasi : RSAL Surabaya

Peserta: Dokter muda Universitas Hang Tuah

Perihal: Pemahaman dan kelayakan perancangan termasuk desain dan animasi melalui gimmick.

\section{KONSEP DESAIN}

\section{A. Konsep Luaran}

Hasil riset menghasilkan konsep luaran sebuah smartphone apps dengan peragaan animasi 3D berbasis augmented reality. Konten pada perancangan ini mengacu pada konten anatomi dan fisiologi urogenital disertai pembelajaran penyakit populer urologi. Isi konten dibagi menjadi dua yaitu pembelajaran anatomi dan fisiologi menggunakan augmented reality, dan peragaan penyakit pada organ urogenital.

\section{B. Spesifikasi Teknis}

1) Output pada apps ini berupa 3D guidelines sebagai dengan markerless AR dengan ukuran resolusi yang tentatif dengan rasio dasar 16:10 (1080x1920 px)

\section{Konten}

2) Konten AR meliputi 9 organ urogenital yang diringkas menjadi 5 bagian (ginjal+ureter, kandung kemih, prostat, penis + urethra, testis + vas deferens + epididimis)

3) Konten peragaan $3 \mathrm{D}$ meliputi 5 penyakit populer (batu saluran kencing, kanker prostat, vesicoureteral reflux, kanker kandung kemih, inkontinensia urine)

D. Logo

Logo yang terpilih akan merujuk pada gambar tampak samping organ urogenital (ginjal) yang akan ditampilkan pada gambar (2) beserta alternatifnya.
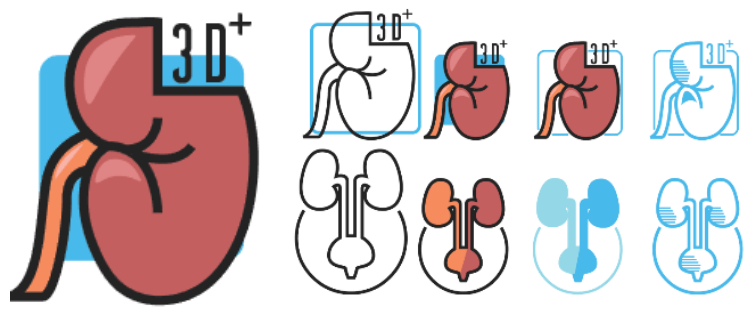

Gambar 2. Logo yang terpilih beserta alternatif.

Alternatif logo ke pertama dipilih karena korelasinya yang paring dekat dengan topik perancangan aplikasi dan tujuan aplikasi yaitu panduan untuk mengetahui penyakit populer pada urologi untuk dokter muda urologi. 


\section{E. Warna}

Pada gambar (3) dapat dijelaskan bahwa warna yang digunakan sangat variatif. Warna yang digunakan secara umum yaitu dominan putih dengan aksentuasi biru muda dan merah bata karena mewakili aksentuasi ginjal dan warna umum yang ada di urologi.
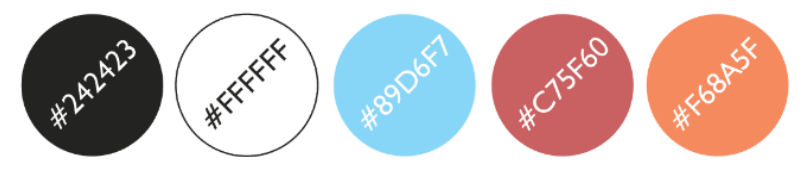

Gambar 3. acuan warna yang digunakan untuk perancangan.

Warna Putih memberikan keterbacaan dan kejelasan, sedangkan warna biru muda memberikan kesan muda dan kejelasan. Untuk warna merah bata memberikan kesan sebagai penunjuk karena warna merah bata identic seperti warna organ. Dan jingga sebagai aksentuasi kecil.

Warna cokelat tua digunakan sebagai warna judul pada teks dan aksentuasi kecil karena warna ini dianggap memberikan ketegasan. Sehingga diharapkan pengguna dapat melihat citra aplikasi yang terpercaya.

\section{F. Refrensi ilustrasi dan $3 D$}

Refrensi pada perancangan ini digunakan sebagai image target dari AR dan model 3D. Ilustrasi ini mengacu pada refrensi ilustrasi ‘Netter atlas of human anatomy' yaitu ilustrasi realis. Ilustrasi ini terpilih karena organ yang digambar sangat detail.
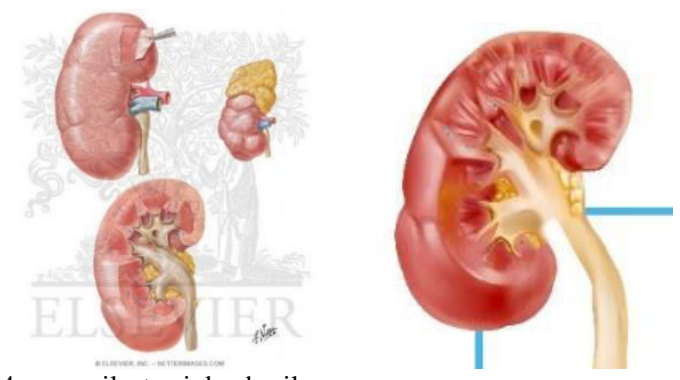

Gambar 4. acuan ilustrasi dan hasil
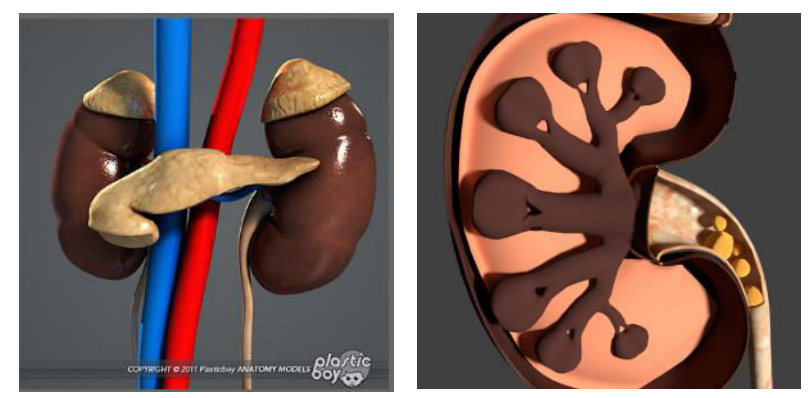

Gambar 5. acuan model 3D dari refrensi ilustrasi serta hasilnya

\section{G. Desain Antarmuka}

\section{1) Alur Akses}

Gambar (6)(7)(8) merupakan skema alur akses dalam aplikasi ini yang terdiri dari menu awal, tombol 3D, dan tombol AR+. Masing-masing tombol menjelaskan fungsifungsi spesifik seperti menu, peragaan 3D dan peragaan $\mathrm{AR}+$
Gambar 6. Alur akses 'menu'.

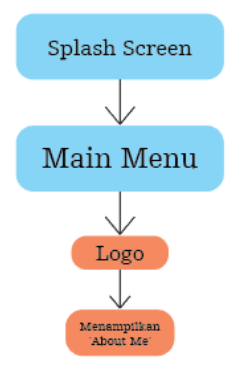

Menu pertama terdapat video bumper, lalu logo 'yourology' besar. Ketika diketuk terdapat informasi dan akses untuk mengunduh image target.

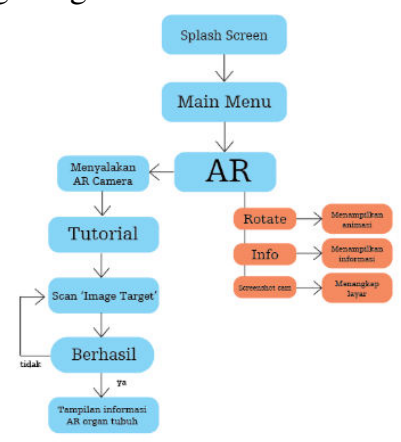

Gambar 7. Alur akses 'AR+'.

Menu AR+ ini dapat mengakses AR Camera sehingga siap memindai image target untuk memunculkan konten 3D dengan augmented reality. Pengguna dapat mengakses 5 organ dengan keterangan lebih spesifik. Pengguna dapat mengetuk model 3D untuk melihat potongan organ.

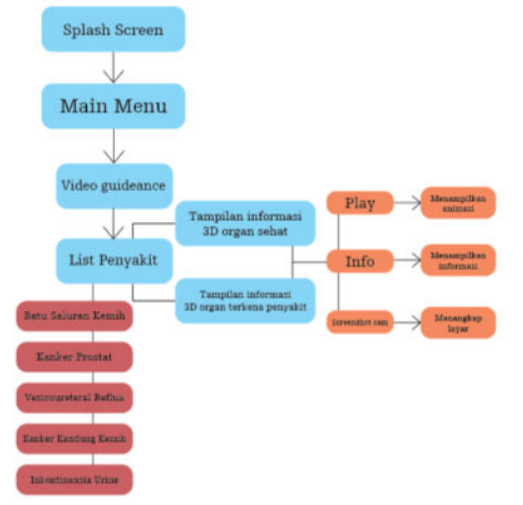

Gambar 8. Alur akses ' $3 D$ '.

Menu 3D ini dapat mengases ke sub menu yang terdapat 5 ikon untuk penyakit populer. Kelimanya terdapat perbandingan organ yang sehat dan tidak sehat, lalu keterangan lebih lanjut mengenai penyakit tersebut. Pengguna dapat menangkap layar ketika melakukan interaksi

2) Elemen antarmuka

Bedasarkan observasi, elemen antarmuka mencakup pada tipografi, icons, AR info bar, 3D bar, dan supergrafis.

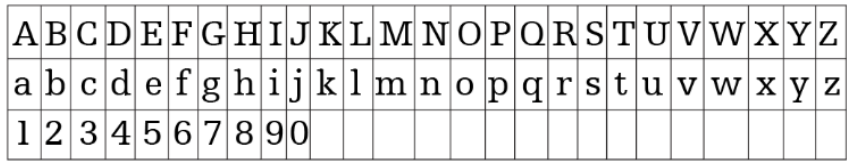

Gambar 9. Contoh tipografi 'Humanist slabsherif 712' untuk judul dan heading (sumber: identifont.com) 


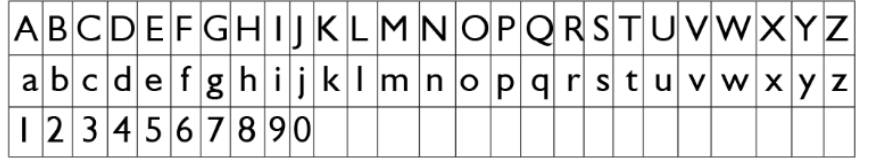

Gambar 10. Contoh tipografi 'Humanist 512' untuk isi / konten.

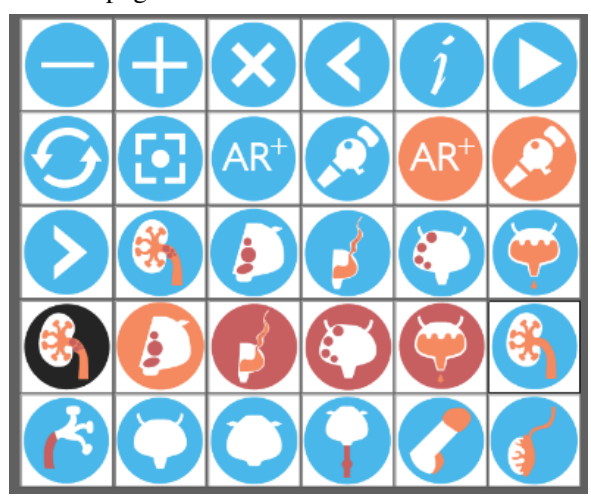

Gambar 11. ikon antarmuka.

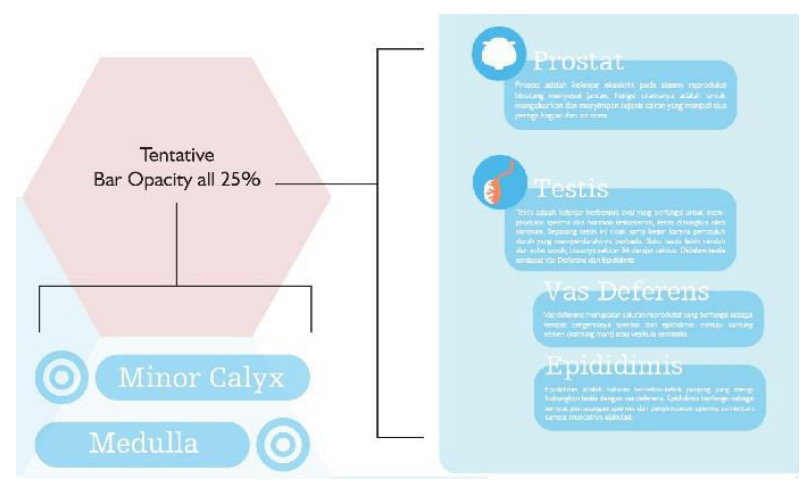

Gambar 12. contoh AR info bar.

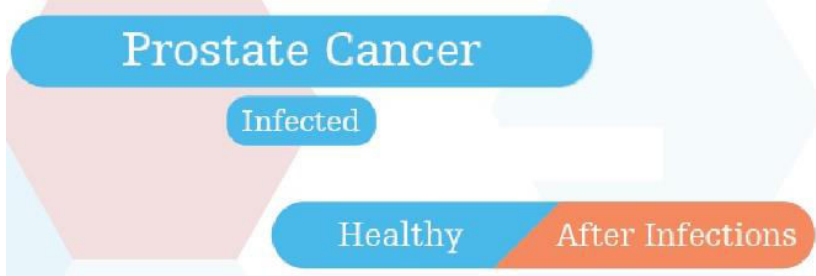

Gambar 13. contoh 3D bar.

Inti

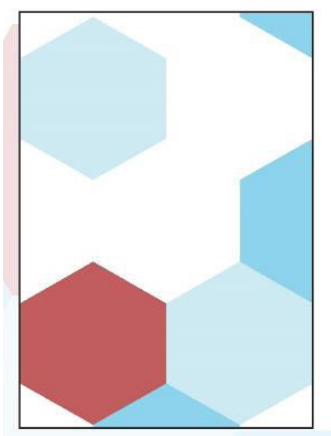

Gambar 14. contoh supergrafis serta contoh implementasi pada apps.

\section{PEMBAHASAN DESAIN}

Hasil akhir desain berupa smartphone apps dengan peragaan animasi 3D berbasis augmented reality dengan brand bernama "Yourology"

\section{A. Hasil akhir antarmuka menu}

Main Menu

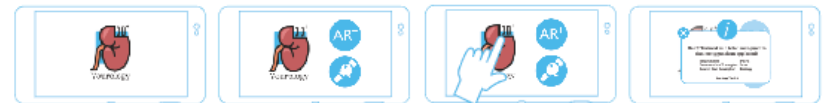

Gambar 15. hasil akhir antarmuka 'menu'.

Pada menu pertama terdapat video bumper lalu menu untuk memilih 2 sub-menu konten lainnya dan logo 'Yourology' besar. Ketika menuju ke logo, terdapat informasi tentang aplikasi ini. Lalu ketika mengakses logo $A R+$ akan langsung tertuju ke $A R$ camera, dan ketika mengakses ke logo dibawahnya akan langsung ke sub-menu 3D

\section{B. Hasil akhir menu $A R+$}

AR
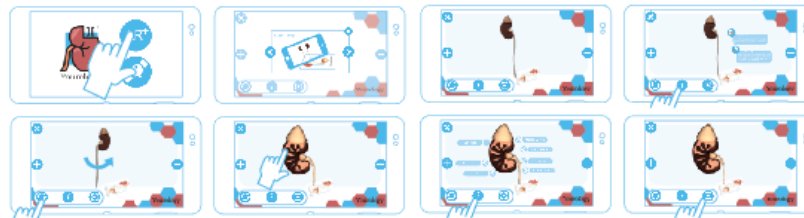

Gambar 16. hasil akhir antarmuka 'AR+'.

Menu $A R+$ ini dapat mengakses $A R$ Camera sehingga siap memindai image target untuk memunculkan konten $3 \mathrm{D}$ dengan augmented reality. Pengguna dapat mengakses 5 organ dengan keterangan lebih spesifik. Pengguna dapat mengetuk model 3D untuk melihat potongan organ.

\section{Hasil akhir menu peragaan $3 D$}

3D
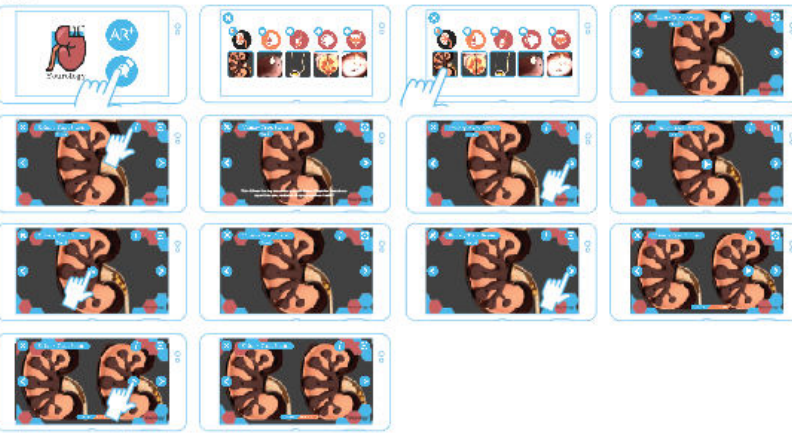

Gambar 17. hasil akhir antarmuka ' $3 D$ '.

Menu $3 D$ ini dapat mengases ke sub menu yang terdapat 5 ikon untuk penyakit populer. Kelimanya terdapat perbandingan organ yang sehat dan tidak sehat, lalu keterangan lebih lanjut mengenai penyakit tersebut. Pengguna dapat menangkap layar ketika melakukan interaksi

\section{Hasil akhir ilustrasi untuk image target}

Hasil akhir pada ilustrasi tetap menggunakan refrensi dan acuan gaya gambar 'realis' agar detail sub organ terlihat jelas. 


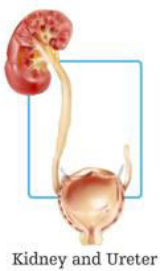

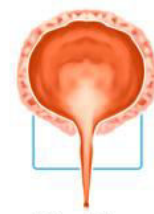

Bladder
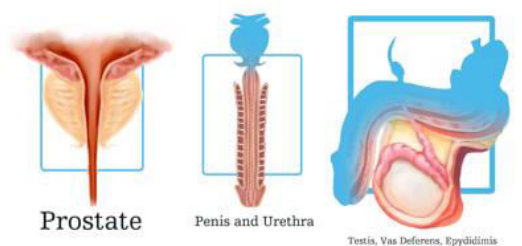

Gambar 18. hasil akhir ilustrasi untuk image target.

\section{E. Hasil akhir 3D sebagai peragaan}

Hasil akhir pada animasi 3D berupa animasi motion yang menunjukkan gerakan pergerakan objek, perbesaran objek, dan penambahan objek lain.

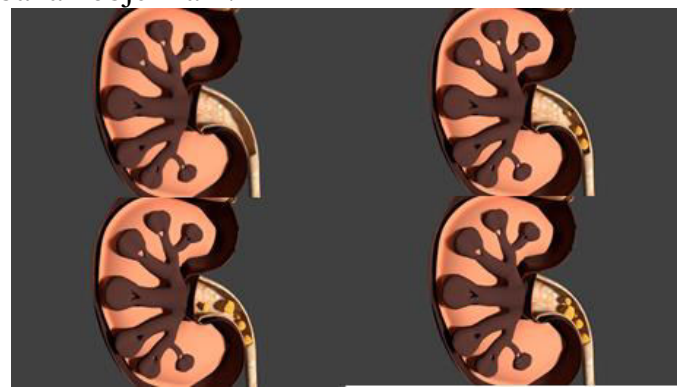

Gambar 19. timeline hasil akhir pada batu saluran kemih.

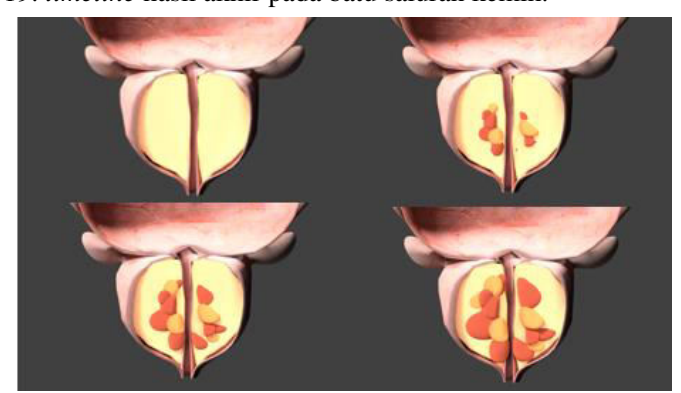

Gambar 20. timeline hasil akhir pada kanker prostat.

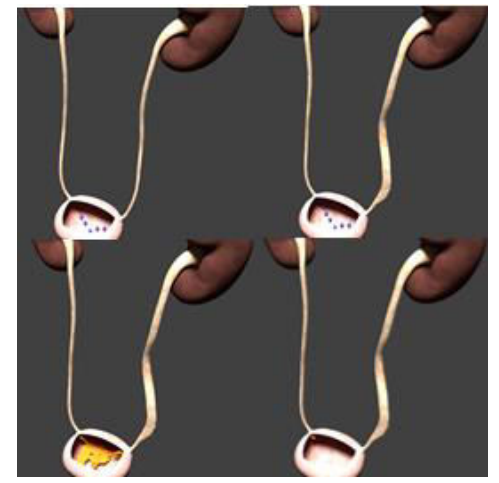

Gambar 21. timeline hasil akhir pada vesicoureteral reflux.

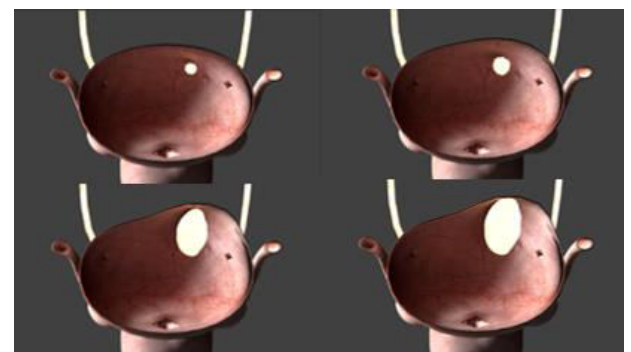

Gambar 22. timeline hasil akhir pada kanker kandung kemih.

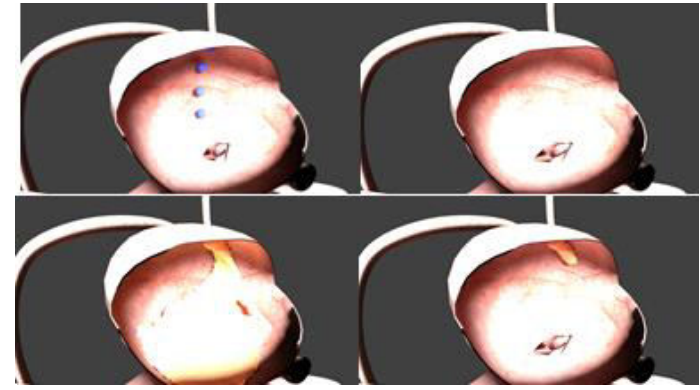

Gambar 23. timeline hasil akhir pada inkontinensia urin.

\section{KESIMPULAN}

Kesimpulan dari perancangan ini yaitu 'Yourology' merupakan aplikasi smartphone untuk pembelajaran urologi manusia dengan peragaan animasi 3D berbasis augmented reality. Tujuan utama dari perancangan ini yaitu untuk mendampingi sitem pembelajaran pada mahasiswa kedokteran dan dokter muda stase bedah urologi.

Pada antarmuka perancangan terdapat 1 segmen lain berupa main menu dan 2 segmen inti yaitu AR dan 3D. Pada segmen AR terdapat 5 organ urogenitalia yang bertujuan untuk memberikan peragaan dalam anatomi / fisiologi. Lalu pada 3D terdapat 5 penyakit populer untuk memberikan simulasi penyakit sebagai peragaan pembelajaran.

3D model yang digunakan pada peragaan menggunakan model yang detail untuk memberi kejelasan pada organ beserta sub-organnya. Lalu pada peragaan 3D dilengkapi motion animation guna untuk memperagakan sebuah penyakit lebih jelas.

Elemen desain seperti logo, ikon, dan supergrafis yang dipilih mengarah kepada flat design karena flat design menggambarkan praktis, dan keringkasan (simplicity)

Bentuk geometris supergrafis dengan ikon berbeda dikarenakan bentuk supergrafis menggambarkan futuristik dan identitas sekunder dari perancangan, dan bentuk ikon menggambarkan kejelasan dikarenakan ikon bersentuhan langsung dengan antarmuka.

Warna yang dipilih bertujuan untuk memberikan kesan terpercaya, jelas, dan senada dengan logo 'Yourology'

Dengan adanya perancangan ini, penulis berharap dapat membantu target audience sebagai pendamping dan peragaan pembelajaran dalam memahami urologi, organ urogenitalia, dan 5 penyakit populer.

\section{DAFTAR PUSTAKA}

[1] J. A. Jacko and A. Sears, Handbook of Research on Ubiquitous Computing Technology for Real Time Enterprises. CRC Press, 2003.

[2] D. Luebke and dkk, Level of Detail for 3D Graphics. 2003.

[3] O. Bimber and R. Raskar, Spatial Augmented Reality: Merging Real and Virtual Worlds. CRC Press, 2005.

[4] S. W. Ambler, User Interface Design: Tips and Techniques. Cambridge University Press, 1998. 